\title{
INVENTORY REDUCTION AND IMPROVEMENT IN MATERIAL STORAGE \& HANDLING WITH THE USE OF LEAN PRACTICES
}

\author{
Akshay Pawar \\ Department of Management Studies \\ K. K. Wagh College of Engineering, \\ Education and Research, \\ Nashik, Maharashtra, India
}

\begin{abstract}
This paper focus on material feeding of hardware kitting which is going to be applied in industry. With the principle of hardware kitting the location of hardware on Kanban rack can be removed and they will be available in kits. By this research and implementation this alternative in industry we can save time and that time can be utilize somewhere else. Today in this competitive world where the demand for each product or current manufactured product is very high, so small issues are too important. Continuous material supply will increase our inventory value, time will be more for operators to work on and searching time will be increased. This research is done by collected data physically by visiting each work stations for different product specifications. Each and every objective in this research will be useful for better industrial solution.
\end{abstract}

Keywords - Hardware kitting, sub assembly kitting, material feeding.

\section{INTRODUCTION}

In today's world every company look for their high production and according to their production how their production is satisfying their customers by improving their their delivery. For achieving this they need keep their cost and prices low as compared to others, but their profit should be increased. Lean concept help companies not only to keep proper arrangements but also help them to combine the improvement in production, proper utilization in operational and commercial aspects and manage the continuous production. Kitting is practiced as a method of materials feeding among others such as continuous supply, batching and sequencing. The practice of looking for same type of hardware required in equal number in each product specification can be made into kits and this kits can be used at different workstation to less down the working time. Rather than bring different hardware by workers on work

\author{
Tejashree Gaikwad \\ Department of Management Studies \\ K. K. Wagh College of Engineering, \\ Education and Research, \\ Nashik, Maharashtra, India
}

station, the kits will be brought to the workstation by supplier by kitting it from his own responsibility as per our purchase order. The box will be provided to him as per our work stations with number of hardware according to it. One reason for combining kitting with continuous supply is to achieve the space savings at the assembly stations, associated with kitting, while at the same time not having to spend more time for unnecessary packing of parts into kits.

\section{RESEARCH OBJECTIVE}

- To prepare hardware kit resulting in reduction of storage space, inventory, mismatch, pilferage.

- To identify potential items/assembly and offload assembly work to suppliers to improve throughout time.

- To implement JIT supplies, to ensure seamless supplies, reduced inventory and storage space reduction.

- To reduce stock levels resulting in storage pallet optimization and implementation of trolley for bulky material.

- To improve store aesthetics by using uniform pallets, bins and identification sticker.

- To use QR code stickers for outdoor fabrication to reduce environmental impact and to have better traceability in value chain.

\section{BACKGROUND AND STATEMENT OF PROBLEM}

The objective is to use the method to demonstrate how lean manufacturing principles when used correctly, can help the industry to low down the rate of waste elimination, increase productivity and quality of product, reduce lead time and obtain better overall financial and operational control. The reduction in stock levels and pallet optimization are necessary 


\section{International Journal of Engineering Applied Sciences and Technology, 2019 Vol. 4, Issue 3, ISSN No. 2455-2143, Pages 114-116 \\ Published Online July 2019 in IJEAST (http://www.ijeast.com)}

for improvement in stores. There are lots of problem regarding sub assembly kits. The parts are coming to work stations separately by this we are experiencing a lot of wastage in time as the worker firstly have to assemble sub part and then he can fix it in main assembly. There are also issues regarding hardware kitting as each hardware is coming from different supplier and lot of space is acquired by that hardware on shop floor.

\section{HYPOTHESIS}

- $\quad$ Kitting is very beneficial for manufacturing industry to save their working time.

- H0: There is no association between lean practices and improvement in material storage.

- H1: There is association between lean practices and improvement in material storage.

- Sub assembly kits will save the throughout time at each work stations.

- H0: There is no association between making sub assembly kits for saving throughout time.

- H1: There is association between making sub assembly kits for saving throughout time.

- Implementation of JIT will ensure seamless supplies, reduce inventory and storage space reduction.

- H0: There is no association between implementing JIT and reduction in inventory with storage space.

- H1: There is association between implementing JIT and reduction in inventory with storage space.

- Improvement of store can be done by improving store aesthetics and pallet optimization.

- H0: There is no relation between aesthetics, pallet optimization and improvement in stores.

- H1: There is relation between aesthetics, pallet optimization and improvement in stores.

- QR code stickers will reduce environmental impact and will have better traceability.

- H0: There is no association with QR code application for reduction in environmental impact with better traceability.

- H1: There is association with QR code application for reduction in environmental impact with better traceability.

\section{RESEARCH METHODOLOGY}

A) Type of research

- This minor research will be qualitative as well as quantitative. Exploratory research design is used.

B) Method of study

- Secondary and primary data collection methods used to collect the data.

C) Research Design

- Secondary data is collected through websites, research papers and $\mathrm{ABB}$ website.

- Primary data is collected by visiting several work stations and Kanban rack for collection of various information regarding different components used for assembly of breakers.

- Data Analysis is done by sorting maximum component required, minimum component required and by taking their difference. We will make the kits for maximum component required.

D) Data collection methods and instruments

- Observing and recording data by visiting manufacturing work stations.

- Collection of data with close ended methods (face to face interviews, CAPI, etc.)

Face to face interviews

- Face -to -face interviews with workers at each work station for asking them about information regarding hardware requirement. I have asked one worker to collect one piece of each hardware from each of the work station and collected information about it from Kanban rack. The main advantage behind this was, we find correct information about each PS by collecting data physically and disadvantage was that it takes much more time to collect that information and there was disturbance in their continuous work.

Computer Assisted Personal Interviewing (CAPI)

- It is the form of personal interviewing, but instead of filling a questionnaire, the interviewer bring his laptop along with him and fill data there itself by asking that specific person. The interviewer fill all data in database and which will be further beneficial to them. It is very good rather than filling hundreds of questionnaire. This type of interview technique is very expensive and the interviewer must know how to use database and other computer skills. 
International Journal of Engineering Applied Sciences and Technology, 2019

Vol. 4, Issue 3, ISSN No. 2455-2143, Pages 114-116

Published Online July 2019 in IJEAST (http://www.ijeast.com)

\section{IMPORTANCE OF RESEARCH}

- This all improving methods are very beneficial for company to increase their productivity. This will increase their efficiency to work. It will help in easy counting. It will help in reducing handling time.

- There is lot of issues regarding mismatching of components or hardware, this research will enable a way to reduce the mismatching issues. The factory space should be well utilized and such methods should be implemented that will reduce space on shop floor and that space would be taken by some other important projects. They are planning to implement a project related to hardware kitting, by which there will be space reduction of approximately 20sq.mtr. By this inventory counting will be very easy.

- Sub assembly kits are prepared, in which separate components will be kit together and with the help of time study we noticed that the time required is less than before it was calculated.

- Implementation of JIT will be very beneficial for the organization as it reduce the inventory to be stored. The inventory will remain with the suppliers and it will be available directly when demanded.

- The store will be well maintained, as its stored related aesthetics will be improved. So that the stickers pasted will look similar on the pallets and will be easy for workers to identify the material in it.

\section{CONCLUSION}

- Hardware kits are prepared by which we can save time at line location.

- Sub assembly kits are prepared by which we can save assembly time required for pre assemble the hardware.

- Stickers on the pallets are stick by which their will easy identification for workers to know which material is put in that specific pallet.

- QR code for each finished product will be very effective to know the PS (product specification) where it is manufactured, where its service can be done.

\section{REFERENCE}

- Jitendra Mandloi \& Mr. Abhishek Yadav (2014), Productivity Improvement by Lean Manufacturing an Automobile Industry with the Help of Method Study

- M. Alper Corakci(2008), An Evaluation of Kitting Systems in Lean Production, University college of Boras, school of engineering, SE 50190 BORAS.

- Robin Hanson(2012), In-plant materials supply: Supporting the choice between kitting and continuous supply, Department of Technology Management and Economics CHALMERS UNIVERSITY OF TECHNOLOGY Gothenburg, Sweden 2012

- Mr. Mehul Mayatra, Mr. N.D. Chauhan, Mr. Parthiv Trivedi, A literature review on implementation of Lean Manufacturing Techniques, International Journal of Advance Research, Ideas and Innovation in Technology, volume 1 issue 4 . 